\title{
Development of Crossword Puzzles for Auditory Training
}

\author{
Sin Sung Baek, Jae Hee Lee \\ Department of Audiology, Hallym University of Graduate Studies, Seoul, Korea
}

\author{
청능훈련을 위한 가로세로 단어판 개발 \\ 백 신 성·이 재 희 \\ 한림국제대학원대학교 청각학과
}

\begin{abstract}
Purpose: A crossword puzzle is one of the common and familiar activities for adults. The purpose of this study was to develop crossword puzzles as a material of auditory training. In the puzzle, words were answers (target) to the puzzle, and all the target words were placed from left to right and from top to bottom in a crossword grid. As an auditory clue of puzzle, either sentence or a series of words was used to help figure out the answer. Based on pilot study, we selected 112 crossword puzzles, consisting of 503 answer-words (target) words, 503 sentence-hints, and 2,515 word-hints. Methods: To verify validity and difficulty of each item, 20 young and 16 older adults were tested. Using the crossword puzzle, the listener was required to hear word hint and sentence hint that could lead to the answers and say their own answers. Results: Results showed that, in general, the target words were more easily solved with sentence clues compared to series of words. For most of the puzzle items, young and older listeners answered the crossword puzzles correctly. Of 112 puzzles, 12 puzzle items showing less than the score of $80 \%$ were removed. Consequently, 100 crossword puzzles were selected as a final item, consisting of 452 answer (target) words, 452 sentence-hints, and 2,260 word-hints. Conclusion: Overall, the crossword puzzles developed in this study could be useful for adults regardless of age. Since the crossword puzzle is familiar and entertaining activity, it might better maintain motivation of auditory training compared to conventional training activity of word or sentence repetition. Further research is needed to generate a larger database of puzzle items and also to determine the feasibility of the crossword puzzles into the clinical purpose of aural rehabilitation for the hearing impaired.
\end{abstract}

Key Words: Auditory training, Aural rehabilitation, Crossword puzzle.

\section{INTRODUCTION}

보건복지부의 보고(2014)에 의하면 2005년 청각장애인의 수 가 188,000 명이었던 데 비해 2013년에는 273,000명으로 증가하 였고, 그 중 약 $60 \%$ 가 보청기 혹은 인공와우 등의 보장구를 사 용하고 있다고 한다. 보청기의 기술적 발전이 난청인의 장애 극 복에 많은 도움을 주지만 소음상황 속 의사소통을 개선하는 데는 여전히 한계를 가진다. 소음 속 의사소통을 개선하기 위해 보장구 착용과 더불어 청능훈련 등의 청능재활이 수반되어야 하나 청능훈련 도구의 부족 혹은 청능사의 인식 부족 등이 이 에 부정적인 영향을 미치고 있다.

난청인에게 성공적으로 청능재활을 제공하기 위해서는 청능
평가, 보장구 적합 및 상담과 함께 난청인 개개인에게 최적화된 청능훈련을 실시하는 것이 중요하다(Gordon-Salant, 2005; Lee, 2011; Sweetow \& Sabes, 2006). 최근 국내외 다양한 연 구를 통해 음소(Lee, 2011), 단어(Burk \& Humes, 2007; 2008), 문장(Cho et al., 2013; Yeo et al., 2014) 등의 어음을 듣고 따라 말하는 형식의 청능훈련이 어음인지능력을 개선시키는 효과를 가진다고 보고되었다. 이는 서로 다른 연구에서 다양한 종류의 자극음을 사용하였음에도 유의미한 훈련 효과를 확인하였으 므로 청능훈련에 관한 실증적 연구(evidence-based study)의 근거를 제시한 점에서 의의가 있다. 그러나 실제 임상현장에서 한 가지 종류의 자극음만을 30 분 이상 반복하여 듣고 따라하는 청능훈련을 시행할 경우 난청인이 지겨움을 느끼거나 거부감을 
호소할 수 있으므로(Laplante-Lévesque et al., 2010; Sweetow $\&$ Sabes, 2010) 대상자가 흥미를 느끼고 적극적으로 참여할 수 있는 훈련도구를 개발하는 것이 중요하겠다.

청각전문가인 청능사는 난청인의 청능훈련을 계획할 때 탐 지, 변별, 확인, 이해의 청각기술 발달 순서를 기준으로 훈련에 사용할 자극음을 선택하며, 자극음 단위에 따라 음소, 단어 위 주의 상향식(bottom-up) 분석적(analytic) 훈련을 시행하거나 문장 또는 이야기 등으로 구성하는 하향식(top-down) 종합적 (synthetic) 훈련을 시행할 수 있다. 자음 및 음소변별에 초점을 두어 분석적 청능훈련을 시행한 연구(Ferguson et al., 2014; Lee, 2011; Schumann et al., 2015; Waldeon et al., 1981), 문장 을 이용하여 종합적(synthetic) 훈련을 시행한 연구(Kwon, 2014; Yeo et al., 2014), 분석적 훈련과 종합적 훈련을 함께 사용한 연구 (Rubinstein \& Boothroyd, 1987) 모두 청능훈련의 효과를 입 증하였다.

상향식 종합적 청능훈련의 중요성을 고려하여 재택형(homebased) 단기기억 청능훈련을 시행한 결과(Henshaw \& Ferguson, 2013) 훈련에 참여한 보청기 착용 성인군이 5 주간 총 25 회 의 청능훈련을 받은 후 어음인지능력이 유의하게 향상하였다 고 보고하였다. 이는 반복적으로 음소를 변별하거나 단어를 따 라말하는 분석적 훈련법 외에 주의집중, 기억, 연상 등을 필요 로 하는 종합적 훈련법 또한 청자의 의사소통 능력이 개선될 수 있음을 의미한다. 이를 고려하여 본 연구에서는 청자극을 통해 단어 혹은 문장을 듣고 목표단어를 연상하는 형식의 가로세로 단어퀴즈를 이용한 청능훈련 도구를 개발하고자 하였다. 가로 세로 단어퀴즈는 대다수의 성인들에게 친숙하고 난이도 조절이 쉬우며 다양한 수준의 지식에 해당하는 단어를 폭넓게 사용할 수 있다는 장점을 가진다(Littman et al., 2002). 가로세로 단어 퀴즈를 통한 청능훈련은 단순히 반복하여 따라 말하는 것이 아 니라 들은 것을 통해 단어를 연상하고 그 답을 맞추었을 때 훈련 대상자가 자신감과 성취감을 얻는 즐거움까지 제공할 수 있다.

\section{MATERIALS AND METHODS}

\section{1단계: 목표단어 및 단어판 수집}

본 연구에서는 학력에 상관없이 다양한 연령의 대상자가 훈 련에 참여할 수 있도록 초등학생 문헌에서 2 5음절의 단어를 1 차 수집하였다(예시: 등급별 국어 교육용 어휘, 국어사전풀이, 놀이야 공부야 한글, 생각놀이느낌놀이 가로세로 낱말퍼즐 등). 1 차 수집을 통해 총 1,979 개의 단어를 추출하였고, 이를 통 해 총 152 개의 단어판을 예비시안으로 선정하였다. 이때 각 단 어판은 4 개부터 8 개까지 다양한 개수의 목표단어를 포함하였 다. 단어판 제작 시 Microsoft PowerPoint ${ }^{\mathrm{TM}}$ (Microsoft, Seat- tle, WA, USA)를 사용하였고 아래의 규칙에 기반하여 제작하 였다.

(1) 각 목표단어는 문장힌트 혹은 단어힌트를 듣고 연상 가 능하도록 제작하였다.

(2) 일반적인 단어퀴즈와 마찬가지로 네모 한 칸당 글자 하나 가 들어가게 하였다.

(3) 가로세로 단어퀴즈를 풀 때 단어순서는 네모 칸의 왼쪽 상단에 숫자로 기입하였고, 가로단어는 빨간색 숫자로, 세로단어는 파란색 숫자로 시각적으로 구별할 수 있게 하 였다.

(4) 각 단어의 길이를 한눈에 쉽게 알 수 있도록 단어가 들어 가지 않는 칸은 노란색 혹은 연두색으로 음영을 삽입하 였다.

(5) 각 단어판에서 첫 단어를 맞추어야 할 때 그 단어의 첫 글 자를 볼 수 있도록 단어판에 제시하였다. 즉, 훈련대상자 가 처음으로 맞추어야 할 목표단어가 “유모차”인 경우, "유모차"의 첫 글자인 "유"를 단어판에서 확인할 수 있도 록 하였다.

본 연구에서 개발한 단어판의 예시로 4 개의 목표단어를 포 함하는 단어판은 Figure 1 의 왼쪽에, 5 개의 목표단어를 포함하 는 단어판은 Figure 1 의 오른쪽에 제시하였다. Figure 1 의 왼쪽 단어판의 경우, 유모차 $\rightarrow$ 모자 $\rightarrow$ 오리 $\rightarrow$ 병아리의 순서로 목 표단어를 순서화한 예시이다. 첫 번째 목표단어인 "유모차"가 가로단어였으므로 빨간색 숫자 1이 네모 안 오른쪽 상단에 등 장하였고, 두 번째 목표단어인 “모자”는 세로단어였으므로 파 란색 숫자 2 가 기입되었다. Figure 1의 오른쪽 단어판의 경우 놀부 $\rightarrow$ 부채 $\rightarrow$ 채소 $\rightarrow$ 소금 $\rightarrow$ 금붕어의 순서로 목표단어가 제시되었다.

예비 실험을 통해 청각전문가 2 명이 152 개의 예비시안 단어 판 단어를 모두 검토한 후 이해하기 어렵거나 부적절하다고 생 각되는 단어를 삭제하였다. 실험 결과를 토대로 1,979 개의 단 어 중 503 개의 목표단어를 2 차 수집하였고, 503 개의 목표단어 를 포함하는 112 개의 훈련용 가로세로 단어판을 제작하였다. 총 112 개의 단어판 중 57 개의 단어판은 4 개의 목표단어를 포함 하였고(총 228 개의 목표단어), 55 개의 단어판은 5 개의 목표단 어로 구성되었다(총 275개의 목표단어).

\section{2단계: 문장힌트 및 단어힌트 수집}

위의 1 단계 과정을 통해 선정한 503 개의 목표단어를 연상하 는 데 필요한 문장힌트와 단어힌트를 수집하였다. 힌트로 사용 할 문장 혹은 단어가 목표단어를 연상하는 데 적합해야 하므로 먼저 각 목표단어의 국어적 정의를 조사하였다. 국립국어원의 "국어사전풀이, 등급별 국어 교육용 어휘, 위키백과, 두산백과 
Figure 1. Example of crossword puzzles developed for auditory training. A: Crossword puzzle consisting of 4 target words. B: Crossword puzzle consisting of 5 target words (colors in online).
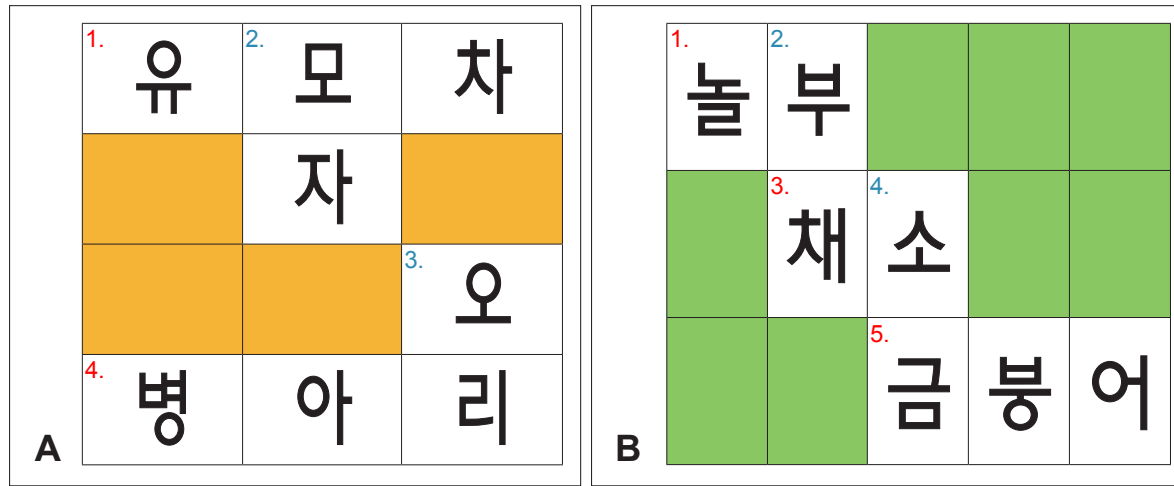

사전” 등의 다양한 국어사전을 사용해 목표단어의 정의를 조 사, 비교 및 취합하였다. 문장힌트, 단어힌트의 수집 및 선정을 위한 세부사항은 다음과 같다.

\section{문장힌트 수집}

문장힌트 선정을 위해 각 목표단어당 두 개의 문장힌트 후보 를 수집하고자 하였다. 1단계 과정에서 총 503개의 목표단어가 선정되었으므로, 503 개의 목표단어를 연상하는 데 필요한 총 1,006 개의 문장힌트를 1 차로 선정하였다. 20 대의 건청 성인 5 명 을 대상으로 예비실험을 진행하여 2개의 문장힌트 후보 중 문 장이 자연스럽고 목표단어를 보다 쉽게 연상할 수 있는 1 개를 최종 선택하였다. 이를 통해 503개의 목표단어를 연상하는 데 사용할 총 503개의 문장힌트를 선정하였다(예시: 목표단어-“유 모차”, 문장힌트-“어린아이를 태워 밀고 다니는 것입니다.”)

\section{단어힌트 수집}

목표단어를 연상하는 데 제시할 일련의 단어힌트를 선정하고 자 각 목표단어당 10 개 미만의 단어힌트 후보를 1 차 추출하였 다. 예비 실험을 통해 10 개 미만의 단어힌트 후보 중 목표단어 를 보다 쉽게 연상할 수 있는 5 개의 단어힌트를 추출하였고, 각 목표단어를 연상하는 데 있어 가장 용이한 순서로 단어힌트의 제시 순서를 선정하였다. 1 단계 과정에서 총 503 개의 목표단어 를 선정하였으므로, 503 개의 목표단어를 연상하는 데 필요한 단어힌트는 총 2,515개였다(예시: 목표단어-“유모차”, 단어힌 트-“아기, 외출, 수레, 바퀴, 이동수단”).

\section{3단계: 음원 녹음}

위의 1 2단계 과정을 통해 선정한 총 503 개의 목표단어, 503 개의 문장힌트, 2,515 개의 단어힌트를 녹음하였다. 한국어 표 준말을 사용하는 20 대 여성이 화자로 참여하였고, 녹음은 Computerized Speech Lab(CSL ${ }^{\mathrm{TM}}$, model 4500; Kay Elemetrics Corporation, Pentax, NJ, USA) 장비와 마이크(SM48$\mathrm{LC}$, Shure, USA)를 사용하였다. 녹음 시 마이크와 화자의 입
간 거리는 $10 \mathrm{~cm}$ 가 되도록 하였고, 음원 제작 시 사용한 표본 화 주파수와 비트는 22,050 Hz, 16 bits 이상으로 하였다. Adobe Audition version 3.0 (Adobe system Inc., San Jose, CA, USA)을 통하여 음원의 강도를 조절하였고, 단어힌트의 경우 5 개가 연속으로 제시되므로 단어힌트의 간격이 1 초가 되도록 조 정하였다.

\section{4단계: 최종 목표단어 및 힌트 선정}

\section{도구 검증에 참여한 대상자 정보}

앞의 과정에서 제작한 가로세로 단어판과 음원을 듣고 청자 가 목표단어를 옳게 맞출 수 있는지 난이도를 검증하고자 하였 다. 특히 청능훈련에 참여할 난청대상자가 주로 50 60대임을 고려하여 본 연구에는 20 30대 성인(평균: 27.7세) 20명, 50 60 대 성인(평균: 56.5 세) 16 명, 총 36 명의 성인이 참여하였다. 순음 청력검사와 어음청각검사 결과(GSI 61, Grason-Stadler, Eden Prairie, MN, USA) 20 30대 대상자 모두 $250 \sim 8,000 \mathrm{~Hz}$ 내 옥타브 단위의 주파수에서 순음청력역치가 $20 \mathrm{~dB} \mathrm{HL}$ 이하였 고, 한국표준 일반용 단음절어표(Kim et al., 2008)를 이용한 단어인지도 측정 결과 모두 92\% 이상의 점수를 보였다. 50 60 대 대상자의 경우 $500,1,000,2,000 \mathrm{~Hz}$ 평균순음역치는 $30 \mathrm{~dB}$ $\mathrm{HL}$ 이하였고, 단어인지도 측정 결과 대상자 모두 $80 \%$ 이상의 단어인지도를 보였다.

\section{도구 검증 절차}

실제 임상현장에서 소음이 차단된 음향부스뿐 아니라 조용 한 방에서 청능훈련을 시행할 수 있으므로 이를 고려하여 소 음수준이 1 분간 측정했을 때 $50 \mathrm{~dB} \mathrm{~L}_{\mathrm{Aeq}}$ 이하인 방에서 도구 의 검증을 시행하였다(sound level meter, type 2250-L; Brüel \& Kjær, Naerum, Denmark). 먼저 MP3 플레이어(YP-GB70 16 G; Samsung, Seoul, Korea)를 통해 연습음원을 제시하여 피검자가 듣기 가장 편안한 최적강도레벨(most comfortable level, MCL)을 찾았다. 피검자의 정면 약 $60 \mathrm{~cm}$ 거리에 위치한 
Table 1. Mean percent-correct score obtained with word hint and sentence hint

\begin{tabular}{|c|c|c|c|c|c|c|}
\hline & \multicolumn{3}{|c|}{ Word hint (\%) } & \multicolumn{3}{|c|}{ Sentence hint (\%) } \\
\hline & Mean & Median & Range & Mean & Median & Range \\
\hline $20-30$ yrs & 97.9 & 100 & $80-100$ & 98.1 & 100 & $85-100$ \\
\hline $50-60$ yrs & 93.3 & 96.9 & $65.6-100$ & 96.4 & 100 & $71.9-100$ \\
\hline
\end{tabular}

LCD 모니터(B2430H; Samsung, Seoul, Korea)를 위치하였고, 화면에서 첫 번째 목표단어의 첫 글자를 볼 수 있도록 하였다 (첫 번째 목표단어인 "유모차"의 “유"를 제시). 개인별 MCL에서 연습용 단어힌트 혹은 문장힌트를 듣고 목표단어를 맞추는 연 습과정을 거친 후 검증을 시행하였다.

앞서 기술한 바와 같이 5 개의 단어로 구성된 단어힌트 혹은 1 개의 문장힌트를 듣고 목표단어를 연상하게 하였다. 단어힌트 의 경우 5 개의 단어로 구성되므로, 첫 번째, 두 번째, 세 번째 단어힌트를 연속으로 제시하고 목표단어를 연상하게 하였다. 3 번째 단어힌트까지 듣고도 목표단어를 옳게 맞추지 못한 경우, 네 번째, 다섯 번째 단어힌트를 연속하여 더 들려주고 목표단 어를 연상할 기회를 제공하였다. 5 개 단어힌트 모두를 듣고도 정답을 맞추지 못한 경우 해당 목표단어를 연상하지 못한 것으 로 간주하였다. 문장힌트의 경우 목표단어당 한 개의 힌트가 존재하였다. 피검자가 문장힌트를 1 회 듣고 목표단어를 맞추지 못한 경우 1 회 더 제시하였고, 2 차 제시 후에도 목표단어를 연 상하지 못한 경우 틀린 것으로 간주하였다.

각 단어판당 10 점 만점을 기준으로 계산하였고, 4 개의 목표 단어로 구성된 단어판의 경우 한 개의 목표단어당 2.5점씩, 5 개 의 목표가 포함된 단어판의 경우 한 개의 목표단어당 2점씩 점 수화 한 후 백분율로 환산하여 정답률(\%)을 계산하였다. 총 112 개의 단어판 모두를 검증하는 데 약 90 120분가량 소요되었다.

\section{RESULTS}

\section{검증 결과}

총 36 명의 성인이 최적강도레벨에서 2,515 개의 단어힌트, 503 개의 문장힌트의 음원을 듣고 503개의 목표단어(112개의 가로세로 단어판)를 얼마나 옳게 맞추는지 검증하였다. 20 30 대와 50 60대가 단어힌트(word hint), 문장힌트(sentence hint)를 통해 보인 정답률(\%)의 평균 및 범위를 Table 1에 나타 내었다.

20 30대의 경우 단어힌트를 듣고 목표단어를 옳게 연상한 정답률이 평균 97.9\%(범위: 80 100\%)였고, 문장힌트를 듣고 목표단어를 맞춘 정답률이 평균 98.1\%(범위: 85 100\%)였다. 즉 20 30대의 경우 힌트 종류에 상관없이 대부분의 목표단어 를 정확하게 연상할 수 있었음을 의미한다.

50 60대는 단어힌트를 통해 평균 93.3\%(범위: 65.6 100\%)
Table 2. The number of puzzles based on mean of percent-correct score

\begin{tabular}{cccccc}
\hline \multirow{2}{*}{ Score $(\%)$} & \multicolumn{2}{c}{ Word hint } & & \multicolumn{2}{c}{ Sentence hint } \\
\cline { 2 - 3 } \cline { 5 - 6 } & $20-30$ yrs & $50-60$ yrs & & $20-30$ yrs & $50-60$ yrs \\
\hline 100 & 73 & 48 & & 63 & 59 \\
$90-99$ & 35 & 37 & & 48 & 41 \\
$80-89$ & 4 & 15 & & 1 & 11 \\
$70-79$ & 0 & 10 & & 0 & 1 \\
$65-69$ & 0 & 2 & & 0 & 0 \\
\hline
\end{tabular}

옳게 목표단어를 연상하였고, 문장힌트를 통해 평균 96.4\%(범 위: 71.9 100\%) 옳게 목표단어를 연상하였다.

정답률의 평균 수치로 보았을 때 20 30대와 50 60대 모두 $93 \%$ 이상 높은 정답률을 보였으나, 50 60대의 경우 정답률 범 위를 통해 알 수 있듯이 $80 \%$ 미만의 정답률을 보인 단어판도 있었다. 이를 보다 세부적으로 확인하기 위해 정답률 범위 별 단어판 개수를 Table 2에 열거하였다.

단어힌트, 문장힌트에 따라 정답률을 구분하여 살펴보면 전 반적으로 단어힌트보다 문장힌트 제시 시 정답률이 비교적 높 았다. Table 2에 정리하였듯이, 20 30대에게 단어힌트를 제시 한 경우 112 개의 단어판 중 108 개의 단어판에서 $90 \%$ 이상 옳 게 맞추었고, 나머지 4 개의 단어판에서 80 89\%의 정답률을 보 였다. 20 30대에게 문장힌트를 제시한 경우 112 개의 단어판 중 1 개를 제외하고는 모두 $90 \%$ 이상의 정답률을 보였다. 50 60대 의 경우 단어힌트를 통해 총 112 개의 단어판 중 85 개의 단어판 에서 $90 \%$ 이상의 정답률을 보였고, 나머지 27 개의 단어판에서 $90 \%$ 미만의 정답률을 보였다(단어힌트로 80 89\%의 정답률 을 보인 단어판 15 개, $70 ~ 79 \%$ 의 정답률을 보인 단어판 10 개, 65 69\%의 정답률을 보인 단어판 2개). 50 60대에게 문장힌트 를 제시한 경우 총 112 개의 단어판 중 100 개의 단어판에서 $90 \%$ 이상의 정답률을 보였고, 나머지 12 개의 단어판에서 $90 \%$ 미만 의 정답률을 보였다(문장힌트로 80 89\%의 정답률을 보인 단 어판 11 개, $70 ~ 79 \%$ 의 정답률을 맞춘 단어판 1개).

\section{검증 후 최종 단어판 구성}

위 검증 결과를 토대로 1 차 수집한 112 개의 단어판 중 50 60대 대상자가 낮은 정답률을 보인 12 개의 단어판을 제외하 고 총 100 개의 단어판을 훈련용 단어판으로 최종 구성하였다. 최종 확정한 100 개의 가로세로 단어판은 452 개의 목표단어로 구성되며, 452 개의 목표단어를 연상하는 데 활용 가능한 문장 
힌트는 총 452 개(목표단어당 문장힌트 한 개), 단어힌트는 총 2,260 개였다(목표단어당 5 개의 단어힌트).

\section{DISCUSSIONS}

청각장애는 청자의 의사소통에 어려움을 야기하므로 삶의 질을 떨어뜨리고 학습능률과 작업효율 등을 저하시켜 일상생 활뿐 아니라 대인관계에도 부정적인 영향을 미칠 수 있다. 보청 기 또는 인공와우의 보장구 착용이 난청인의 가청정도를 향상 시켜 말소리를 듣는 데 도움을 주나 소음상황이나 다화자가 말 하는 환경에서 난청인은 여전히 어려움을 겪는다.

국내외 다양한 연구(Dubno, 2013; Grenness et al., 2014; Woods et al., 2015; Yeo et al., 2014)에서 청능훈련의 유효성과 환 자중심의 재활(patient-centred audiological rehabilitation)의 중요성을 보고하였다. 실제로 난청인이 청능훈련 혹은 청각재 활에 참여할지 여부를 결정할 때 훈련 내용이 흥미로운지, 훈 련이 너무 어려워 좌절감이나 피로감을 느끼지 않는지 등을 많 이 고려하므로(Laplante-Lévesque et al., 2010) 청능훈련 도구 의 내용의 다양화가 중요하다. 예전에는 주로 청자가 청능재활 센터 및 보청기 센터를 방문하여 종이나 컴퓨터를 활용하여 음 소, 단어 변별에 초점을 둔 분석적(analytic) 훈련법을 주로 사 용하였다면, 최근에는 DVD, 스마트폰, 인터넷 등을 이용하는 재택형 훈련 혹은 분석적 훈련과 종합적 훈련을 함께 시행하는 다양한 방식의 훈련이 소개되었다(Olson et al., 2013; Zhang et al., 2014). Henshaw \& Ferguson(2013)는 단기기억에 중점 을 둔 재택형 상향식 종합적 청능훈련을 시행하였고, 5 주의 훈 련 후 유의하게 인지능력이 개선되었음을 밝혔다. 이를 통해 분 석적 훈련법 외에 주의집중, 기억, 연상 등을 필요로 하는 종합 적 훈련법으로 청자의 의사소통 능력이 개선될 수 있음을 시사 하였다.

본 연구에서는 청자극을 통해 단어 혹은 문장을 듣고 목표 단어를 연상하는 형식의 가로세로 단어퀴즈 도구를 개발하고 자 하였다. 기존의 청능훈련에서는 주로 한두 가지 종류의 자 극음을 제시하고 단순히 들은 것을 따라 말하게 하여 자칫 훈 련에 지겨움을 느낄 수 있다는 단점이 있다. 본 연구에서는 청 자극으로 제시된 힌트를 듣고 목표단어를 연상하는 종합적 훈 련방식을 취하면서 퀴즈를 통해 청자의 흥미를 유발하는 훈련 을 시행하고자 하였다. 특히 청자가 연상을 통해 답을 맞추었을 때 자신감과 성취감을 얻을 수 있어 훈련에 참여의지를 높일 수 있다는 장점이 있다.

본 연구에서는 1 단계로 530 개의 목표단어, 530 개의 문장힌 트, 2,515개의 단어힌트로 구성된 112 개의 단어판을 수집하였 다. 연령에 상관없이 단어판을 훈련에 활용할 수 있을지를 확인
하고자 20 30대 성인 20명, 50 60대 16명을 대상으로 검증하 였다. 검증 결과 20 30대 대상자들은 힌트의 종류에 상관없이 평균 $97 \%$ 이상의 높은 정답률로 목표단어를 옳게 맞추었다. 50 60대 대상자 역시 평균 93\% 이상의 정답률을 보였으나 112 개의 단어판 중 12 개의 단어판에서 $80 \%$ 미만의 정답률을 보였다. 따라서 최종 단어판 선정 시 50 60대 대상자가 낮은 정 답률을 보인 12 개의 단어판은 배제하여, 총 100 개의 가로세로 단어판을 최종 도구로 제작하였다. 100 개의 최종 단어판은 총 452 개의 목표단어를 포함하며, 452 개의 문장힌트와 2,260개의 문장힌트가 목표단어를 연상하는 데 활용 가능하도록 하였다.

50 60대가 비교적 저조한 점수를 보인 단어판의 경우 비교 적 낮은 정답률을 보인 특정 단어들이 포함되어 있었다. 예를 들면, 목표단어가 “코알라"였고 “코알라"를 연상하기 위해 제시 한 단어힌트는 “동물, 오스트레일리아, 나무, 인형, 나무늘보", 문장힌트는 "유칼립투스 잎을 먹고 살며, 오스트레일리아에 사 는 동물입니다.”였다. 20 30대와는 다르게 50 60대의 대상자 가 힌트를 듣고 목표단어 "코알라"를 연상하기 어려웠던 이유 는 평소 50 60대가 흔하게 접하지 않는 단어이기 때문일 것으 로 추정해볼 수 있다. 따라서 단어힌트 혹은 문장힌트를 못 들 어서가 아니라 연상하는 데 어려움을 보이는 특정 단어를 포함 하는 단어판을 최종 단어판에서 삭제하였다. 또 다른 예를 들 면, 목표단어가 “산봉우리”였고 “산봉우리”의 연상을 위해 “산, 꼭대기, 언덕, 협곡, 봉우리"의 단어힌트를 제시하였다. 청자는 "산"이라는 첫 글자를 보고 "산꼭대기”의 오답을 말하기도 하였 다. 본 연구의 가로세로 단어판에서 첫 단어가 단어판에 등장하 므로 청자가 힌트만으로 목표단어를 연상하기 어려울 때는 목 표단어와 첫 글자가 같은 단어 중 의미가 유사한 단어를 오답으 로 말하는 경우가 발생할 수 있음을 확인하였다.

본 연구에서는 단어힌트, 문장힌트를 모두 사용하여 검증을 시행하였으므로 실제 임상에서 이를 활용할 때 두 가지 종류 의 힌트 중 훈련대상자가 더 선호하는 것을 선택하여 목표단어 를 맞추는 것이 가능하다. 소음이 없는 상황에서 소음을 증가 하여 듣기 조건을 어렵게 어렵게 조정하거나 힌트 종류 중 대상 자가 더 어려워하는 것을 선택하여 훈련 난이도를 조정할 수 있 겠다.

본 연구에서는 예비 실험 결과를 토대로 총 100 개의 단어판 을 최종 단어판으로 선정하였다. 100 개의 단어판은 목표단어 452개를 포함하고 있으며, 452 개의 목표단어를 연상하는 데 총 452 개의 문장힌트를 혹은 총 2,250 개의 단어힌트를 사용할 수 있다. 본 연구에서는 20 60대 성인이 단어 혹은 문장힌트로 100 개의 단어판내 단어(452개)를 90\% 이상 옳게 연상할 수 있 음을 확인하였다. 그러나 난청의 정도가 심하거나 중추신경장 애가 동반된 대상자의 경우 가로세로 단어퀴즈 형식의 훈련이 
다소 어려울 수 있다. 따라서 대상자의 난청의 정도 및 종류, 연 령, 인지능력, 교육수준, 기타 장애 등을 고려하여 훈련용 단어 판을 선택하는 것이 중요하겠다. 본 연구에서 개발한 연상퀴즈 뿐 아니라 추후 연구에서 다양한 컨텐츠의 훈련도구를 지속적 으로 개발한다면 비용 감소 등의 장점을 가진 한국형 재택 청능 훈련(home-based auditory training) 도구로 적극 활용할 수 있겠다.

중심 단어 : 청능훈련·청각재활·가로세로 단어퀴즈.

\section{REFERENCES}

Burk, M. H. \& Humes, L. E. (2007). Effects of training on speech recognition performance in noise using lexically hard words. Journal of Speech, Language, and Hearing Research, 50(1), 25-40.

Burk, M. H. \& Humes, L. E. (2008). Effects of long-term training on aided speech-recognition performance in noise in older adults. Journal of Speech, Language, and Hearing Research, 51(3), 759-771.

Cho, Y. Y., Lee, J. H., \& Bahng, J. (2013). Case study of auditory training for an elderly hearing aid user. Audiology, 9(2), 190-194.

Dubno, J. R. (2013). Benefits of auditory training for aided listening by older adults. American Journal of Audiology, 22(2), 335-338.

Ferguson, M. A., Henshaw, H., Clark, D. P., \& Moore, D. R. (2014). Benefits of phoneme discrimination training in a randomized controlled trial of 50- to 74-year-olds with mild hearing loss. Ear and Hearing, 35(4), e110-e121.

Gordon-Salant, S. (2005). Hearing loss and aging: new research findings and clinical implications. Journal of Rehabilitation Research and Development, 42(4 Suppl 2), 9-24.

Grenness, C., Hickson, L., Laplante-Lévesque, A., \& Davidson, B. (2014). Patient-centred audiological rehabilitation: Perspectives of older adults who own hearing aids. International Journal of Audiology, 53(Suppl 1), S68-S75.

Henshaw, H. \& Ferguson, M. A. (2013). Working memory training for adult hearing aid users: study protocol for a double-blind randomized active controlled trial. Trials, 14, 417.

Kim, J. S., Lim, D. H., Hong, H. N., Shin, H. W., Lee, K. D., Hong, B. N., et al. (2008). Development of Korean standard monosyllabic word lists. Audiology, 4(2), 126-140.
Korean Institute for Health and Social Affairs. (2014). The Census for Disabled in Korea. Seoul: Ministry of Health and Social Affairs.

Kwon, Y. J. (2014). Effects of 8-week auditory training: Compressed speech and speech in noise (unpublished master's thesis). Hallym University of Graduate Studies, Seoul.

Laplante-Lévesque, A., Hickson, L., \& Worrall, L. (2010). Factors influencing rehabilitation decisions of adults with acquired hearing impairment. International Journal of Audiology, 49(7), 497-507.

Lee, Y. S. (2011). Effects of training on nonsense syllable performance in noise for older hearing aid users (unpublished master's thesis). Hallym University of Graduate Studies, Seoul.

Littman, M. L., Keim, G. A., \& Shazeer, N. (2002). A probabilistic approach to solving crossword puzzles. Artificial Intelligence, 134, 23-55.

Olson, A. D., Preminger, J. E., \& Shinn, J. B. (2013). The effect of LACE DVD training in new and experienced hearing aid users. Journal of the American Academy of Audiology, 24(3), 214-230.

Rubinstein, A. \& Boothroyd, A. (1987). Effect of two approaches to auditory training on speech recognition by hearing-impaired adults. Journal of Speech and Hearing Research, 30(2), 153-160.

Schumann, A., Serman, M., Gefeller, O., \& Hoppe, U. (2015). Computerbased auditory phoneme discrimination training improves speech recognition in noise in experienced adult cochlear implant listeners. International Journal of Audiology, 54(3), 190-198.

Sweetow, R. W. \& Sabes, J. H. (2006). The need for and development of an adaptive Listening and Communication Enhancement (LACE) program. Journal of the American Academy of Audiology, 17(8), 538-558.

Sweetow, R. W. \& Sabes, J. H. (2010). Auditory training and challenges associated with participation and compliance. Journal of the American Academy of Audiology, 21(9), 586-593.

Walden, B. E., Erdman, S. A., Montgomery, A. A., Schwartz, D. M., \& Prosek, R. A. (1981). Some effects of training on speech recognition by hearing-impaired adults. Journal of Speech and Hearing Research, 24(2), 207-216.

Woods, D. L., Doss, Z., Herron, T. J., Arbogast, T., Younus, M., Ettlinger, M., et al. (2015). Speech perception in older hearing impaired listeners: Benefits of perceptual training. PLoS One, 10(3), e0113965.

Yeo, S. H., Bahng, J. H., \& Lee, J. H. (2014). Efficacy of auditory training using sentences in noise for hearing aid users. Audiology, 10(1), 65-75.

Zhang, M., Miller, A., \& Campbell, M. M. (2014). Overview of nine computerized, home-based auditory-training programs for adult cochlear implant recipients. Journal of the American Academy of Audiology, 25(4), 405-413. 